\title{
COMPUTER GUIDED CHIN REPOSITIONING USING PATIENT SPECIFIC OSTEOTOMY/SCREW HOLES/PLATE LOCATING SURGICAL GUIDES
}

\author{
Mohammed Omara* and Aala'a Emara*
}

\begin{abstract}
Chin surgeries are a very common procedure with the rise in need for appealing esthetics. Genioplasties as with other surgeries mainly depend on accurate copying of the presurgical planning. The aim of this study was to assess the accuracy of chin positing using patient specific osteotomy/ screw hole locating surgical guides in genioplasties. Ten patients with chin deformities/dentofacial non-syndromic deformities were included. The chins were repositioned using osteotomy/screw holes locating and plate locating surgical guides with pre-bent plates. The accuracy of the chin segment fixation was determined by comparing the virtual planned and the postoperative CT scans. All our cases showed accurate radiographic and clinical chin position as compared to the planning with a mean deviation of $0.046 \pm 0.03 \mathrm{~mm}$ which is lower than the reported accepted clinical deviation (1mm). The surgical osteotomy/screw-hole locating guide ,plate/chin segment locating guide and pre-bent plates presented in this study allowed for accurate chin positioning surgeries and better esthetic results.
\end{abstract}

\section{INTRODUCTION}

Facial esthetics and symmetry has gained more public interest lately. The chin is a cornerstone for facial prominence and overall appearance which has led to the introduction of a multitude of chin bone surgeries ${ }^{[1-2]}$. The localization of the osteotomies and fixing armamentarium is of utmost importance to ensure proper post-operative esthetics and acceptable appearance ${ }^{[3-4]}$. Surgical planning for genioplasties is therefore a major reason for the success of genioplasties ${ }^{[5]}$. With the rapid evolution of computer guidance and
3D printing technologies, their application in genioplasties and other orthognathic surgeries has shown excellent results. Surgeons have been able to plan and assess genioplasties and discuss them with the patients ${ }^{[5]}$. Patient specific surgical guides for the osteotomies have been reported and showed positive results allowing for predictable results ${ }^{[6]}$. The printing of surgical guides has been proposed and proven successful, improving the accuracy and positioning of the fixation device ${ }^{[7]}$. The guides are fabricated in a polymer material that is quite cheap, affordable and easily printed using FDM technology.

\footnotetext{
* Lecturer at Oral and Maxillofacial Surgery Department, Faculty of Dentistry, Cairo University, Cairo, Egypt.
} 
These guides are set in place using screws to guide the osteotome saws in the predetermined position for accurate bone cutting ${ }^{[8]}$.

On the other hand, the accurate placement of the final fixation device has not been vastly proposed. The use of patient specific guides for the placement / positioning of the final fixation device and fixation screws should further improve esthetic results of genioplasties. The aim of this study is to propose the use of 3D printed surgical guides for chin osteotomies and final screw hole positioning for segment fixation.

\section{PATIENTS AND METHODS}

This is a prospective study conducted on 10 patients recruited at the Department of Oral and Maxillofacial Surgery, Faculty of dentistry, Cairo University. Recruited patients were non-syndromic with dentofacial deformity requiring chin surgery. Patients with previous jaw surgery, craniofacial anomalies, temporomandibular joint dysfunction or medical conditions contraindicating surgical procedures/anesthesia were excluded from the study.

All enrolled patients were subjected to bimaxillary orthognathic surgeries with primary or secondary genioplasty. Genioplasty was performed in all cases using patient specific osteotomy/plates locating surgical guides and pre-bent titanium miniplates based on preoperative virtual planning and simulation.

\section{Preoperative preparation and virtual planning}

The included patients went through leveling, alignment and dental decompensation preoperatively. Once the presurgical orthodontic phase was done, CT scans were ordered in the natural head position on a multi-slice helical CT machine*. The DICOM files were then imported to the surgical simulation software Mimics ${ }^{* *}$. The virtual 3D models were then calculated and used to confirm eligibility to this study.

\section{Presurgical steps}

The patient's plaster dental casts were then scanned and imported to the surgical planning software. The digital casts in pre and speculated post-operative positions were registered over the dental arches of the virtual 3D model to fabricate a dentate skull model. These steps were followed for all 10 patients included in this study.

After virtual surgeries, the corrected mandibular STL files were sent to an additive CAM machine *** to be printed by FDM technology in white polyamide material $^{* * * *}$. Using this corrected mandibular model; a $2.0 \mathrm{~mm} \mathrm{X}$ shaped titanium miniplate was adapted for guided patient-specific intraoperative fixation. The adapted miniplate placed on the corrected model were then scanned again and imported to specify the screw-hole locations (Figures 1 A, B).

Surgical osteotomy/screw-locating guides, and plate/chin segment-locating guide were also fabricated according to the corrected mandibular virtual model, then printed in white polyamide as above (Figure 2).

\section{Surgical steps}

The chin was exposed intraoperatively with a genioplasty incision. The locating surgical guides for the osteotomies and plate location were fixed in place using 2.0-mm screws (Figures 3 A\& B). The osteotomies were performed using a reciprocating saw alongside the surgical guide (figure 4) and the chin was mobilized, repositioned and fixed using the adapted X-shaped miniplates (figure 5).

\footnotetext{
* (I-CAT ${ }^{\circledR}$ Precise $^{\text {TM }}$ from I-CAT ${ }^{\circledR}$ Technology, Hatfield, PA

** (Mimics 19.0, Materialise NV, Leuven, Belgium)

*** FORMIGA P 110 printer; EOS e-manufacturing solutions, Munich, Germany

**** PA2200; EOS e-manufacturing solutions, Munich, Germany
} 


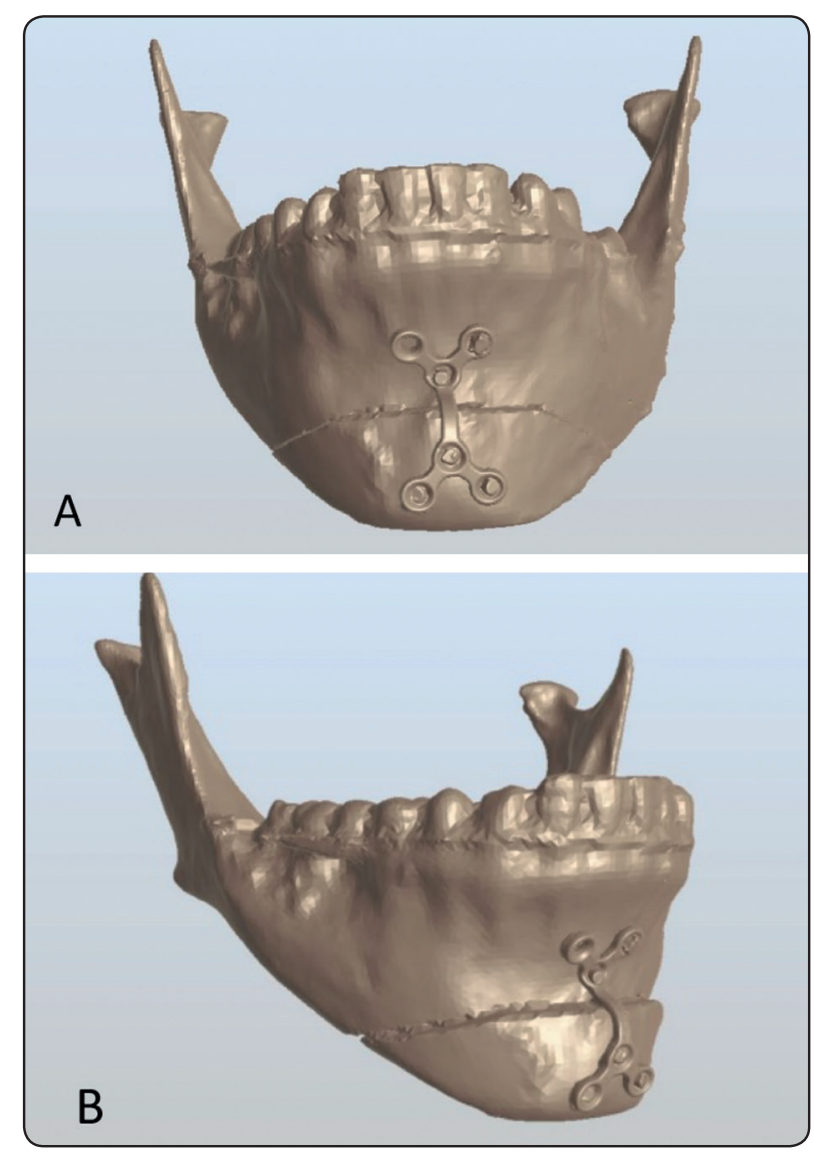

Fig. (1): Showing scanned model of the corrected chin with the adapted plate

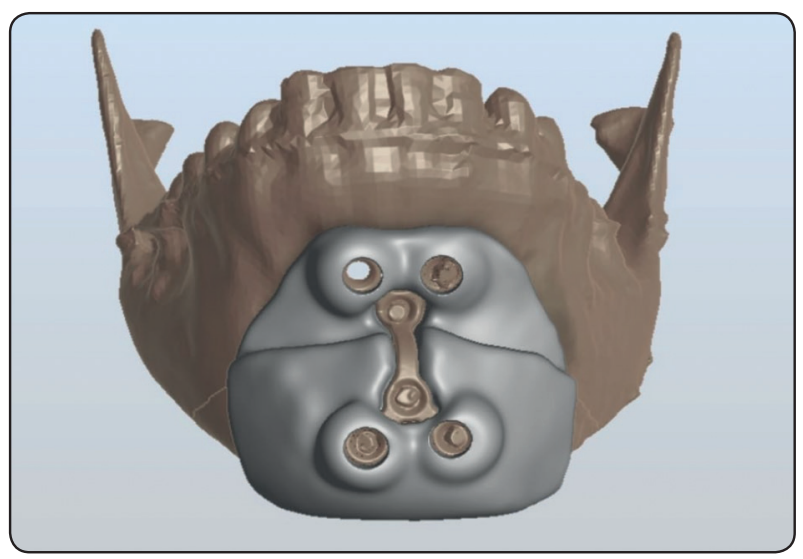

Fig. (2): Plate guide designed according to adapted plate and ready for printing

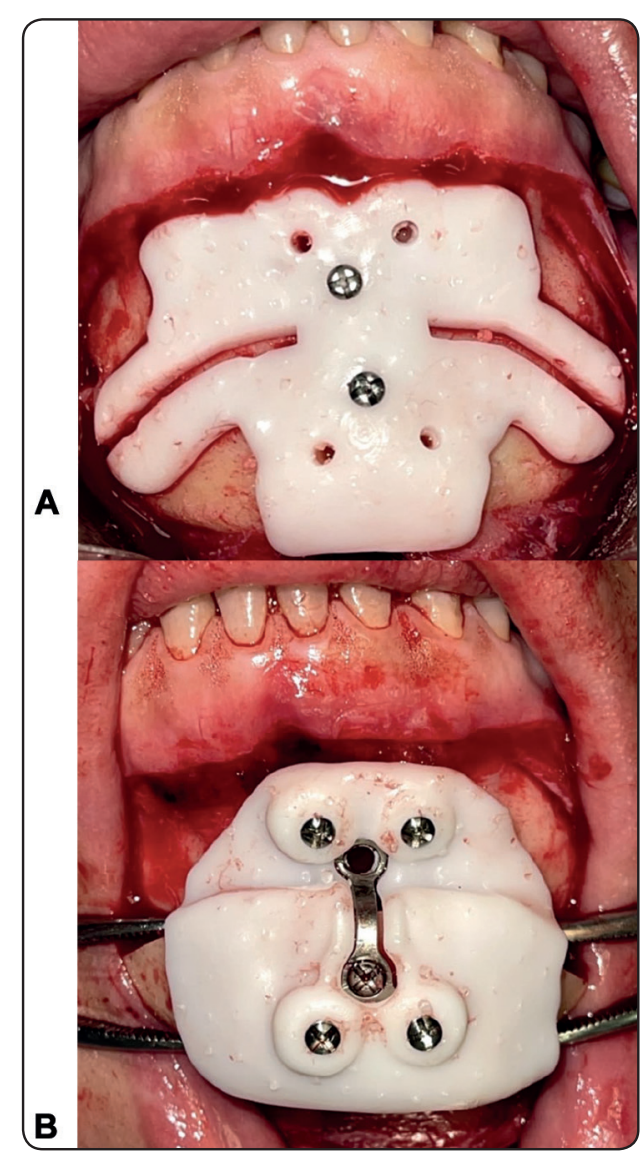

Fig. (3): Patient specific guides fixed in place; A: osteotomy/ screw-hole locating guide, B : plate / chin-segment locating surgical guide.

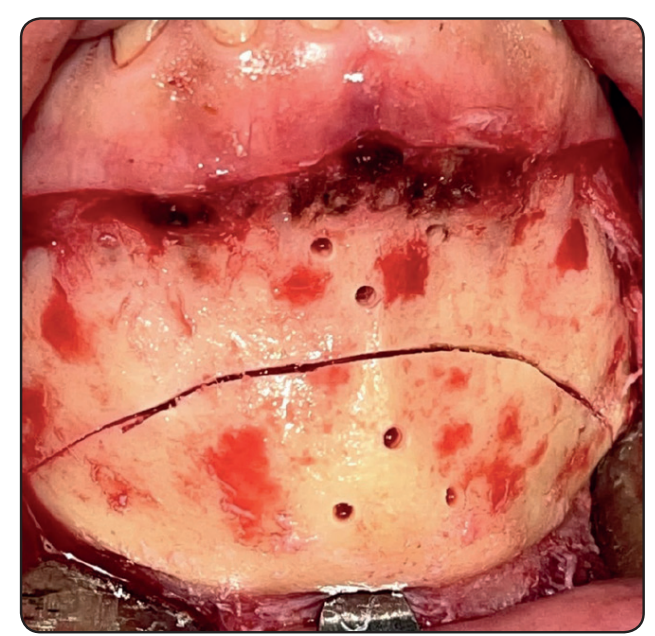

Fig. (4): Osteotomy cuts made and screw-hole located according to the printed guides 


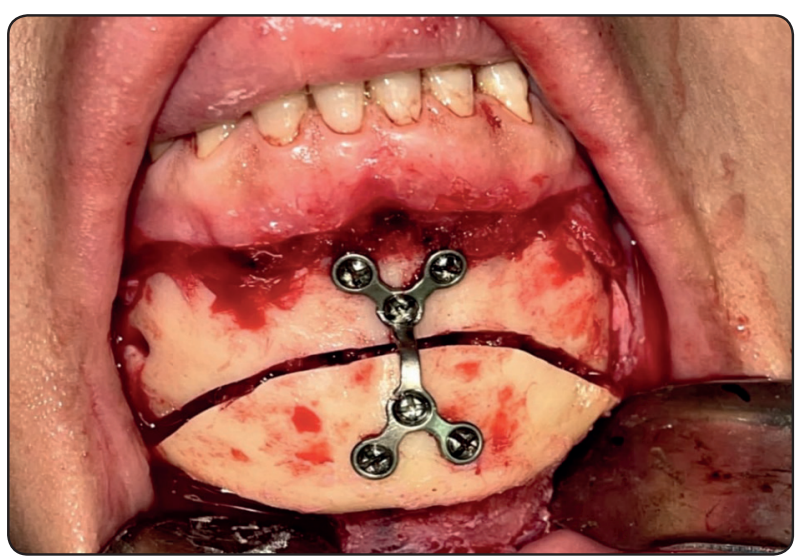

Fig. (5): Mobilized chin fixed in place according to the preplanned screw-holes and pre-adapted X-shaped plate

\section{Outcomes}

One week after surgery, CT scans were reordered with the same specs as the preoperative one to assess accuracy of the virtual surgical plan. Linear and angular deviations were measured on bony reference points after the postoperative model was registered onto the planned model and saved for statistical analysis. The references used were the Frankfurt Horizontal Plane (FHP), Midsagittal Plane (MSP), Coronal Plane (CP), Menton (Me), Pogonion (Po), Point B (B) and the mandibular plane (Ma) for linear and angular deviation measurements. The operative time was also calculated from incision till suturing in all cases. Radiographic measurements were evaluated by 2 assessors and the mean of these readings was used for statistical analysis.

\section{Statistical analysis}

Categorical data were presented as frequencies (n) and percentages (\%) and were analyzed using Fisher's exact test. Numerical data was explored for normality by checking the data distribution, calculating the mean and median values, and using Kolmogorov-Smirnov and Shapiro-Wilk tests. Data showed parametric distribution so; they were represented by mean and standard deviation (SD) values. Statistical analysis was performed with $\mathrm{R}$ statistical analysis software version 4.0.3 for Windows*

\section{RESULTS}

This study was conducted on ten patients (3 males and 7 females) with the mean age of $22 \pm$ 4.67 years of age. Surgical genioplasty was carried out on all patients. All cases were uneventful with normal blood loss and an average surgical operative time of $63 \pm 15.5$ minutes. The mental nerve remained unaffected in all cases. The preoperative virtual planning in four cases showed vertically elongated chin necessitating reduction genioplasty, while five cases required advancement and one case required double sliding genioplasty. In nine of our cases the genioplasty was performed in conjunction with bi-maxillary surgical intervention and only one of our cases was a secondary corrective procedure after bi-maxillary surgical intervention. The follow up of all cases was uneventful; normal healing with no wound dehiscence, no plate exposure, no infection, edema resolved in all cases occurred within 2 weeks.

The corrected chin in all cases showed accurate clinical and radiographic position regarding linear and angular deviations at all analyzed bony reference points and planes three dimensionally (table 1).

Superimposition of postoperative chin over the preoperatively designed plate locating guide showed accurate plate position in all cases (Figure 6).

\footnotetext{
* owing R Core Team (2020). R: A language and environment for statistical computing. R Foundation for Statistical Computing, Vienna, Austria. URL https://www.R-project.org/.
} 
TABLE (1) Anatomical landmark for deviation measurement $(\mu \mathrm{m})$

\begin{tabular}{ccccccccccccc}
\hline Case \# & $\begin{array}{c}\text { Me. } \\
\text { FHP }\end{array}$ & $\begin{array}{c}\text { Me. } \\
\text { MSP }\end{array}$ & $\begin{array}{c}\text { Me. } \\
\text { CP }\end{array}$ & $\begin{array}{c}\text { PO. } \\
\text { FHP }\end{array}$ & $\begin{array}{c}\text { PO. } \\
\text { MSP }\end{array}$ & $\begin{array}{c}\text { PO. } \\
\text { CP }\end{array}$ & $\begin{array}{c}\text { Bp. } \\
\text { FHP }\end{array}$ & $\begin{array}{c}\text { Bp. } \\
\text { MSP }\end{array}$ & $\begin{array}{c}\text { Bp. } \\
\text { CP }\end{array}$ & $\begin{array}{c}\text { Ma. } \\
\text { FHP }\end{array}$ & $\begin{array}{c}\text { Ma. } \\
\text { MSP }\end{array}$ & $\begin{array}{c}\text { Ma. } \\
\text { CP }\end{array}$ \\
\hline $\mathbf{1}$ & 0.02 & 0.06 & 0.07 & 0.02 & 0.07 & 0.04 & 0.05 & 0.07 & 0.03 & 0.05 & 0.03 & 0.08 \\
\hline $\mathbf{2}$ & 0.09 & 0.07 & 0.09 & 0.04 & 0.09 & 0.04 & 0.01 & 0.09 & 0.05 & 0.07 & 0.06 & 0.02 \\
\hline $\mathbf{3}$ & 0.08 & 0.08 & 0.07 & 0.03 & 0.08 & 0.03 & 0.09 & 0.09 & 0.04 & 0.06 & 0.05 & 0.02 \\
\hline $\mathbf{4}$ & 0 & 0 & 0.02 & 0.04 & 0.09 & 0.05 & 0.03 & 0.09 & 0.06 & 0.09 & 0.08 & 0.03 \\
\hline $\mathbf{5}$ & 0.01 & 0.06 & 0.04 & 0.06 & 0.05 & 0.09 & 0.09 & 0.07 & 0.02 & 0.02 & 0.02 & 0.05 \\
\hline $\mathbf{6}$ & 0.06 & 0.07 & 0.07 & 0.01 & 0.07 & 0.01 & 0.03 & 0.08 & 0.02 & 0.07 & 0.03 & 0.02 \\
\hline $\mathbf{7}$ & 0.04 & 0.05 & 0.03 & 0.02 & 0.08 & 0.02 & 0.05 & 0.08 & 0.04 & 0.04 & 0.04 & 0 \\
\hline $\mathbf{8}$ & 0.08 & 0.04 & 0.01 & 0.04 & 0.03 & 0.09 & 0.07 & 0.05 & 0 & 0 & 0.01 & 0.02 \\
\hline $\mathbf{9}$ & 0.02 & 0.05 & 0.04 & 0.08 & 0.06 & 0.01 & 0 & 0.08 & 0.01 & 0.05 & 0.02 & 0.06 \\
\hline $\mathbf{1 0}$ & 0 & 0.05 & 0.02 & 0.05 & 0.04 & 0 & 0.08 & 0.06 & 0.01 & 0.01 & 0.01 & 0.04 \\
\hline Mean & 0.04 & 0.05 & 0.05 & 0.04 & 0.07 & 0.04 & 0.05 & 0.08 & 0.03 & 0.05 & 0.04 & 0.03 \\
\pm SD & \pm 0.03 & \pm 0.02 & \pm 0.03 & \pm 0.02 & \pm 0.02 & \pm 0.03 & \pm 0.03 & \pm 0.01 & \pm 0.02 & \pm 0.03 & \pm 0.02 & \pm 0.02 \\
\hline
\end{tabular}

(FHP-Frankfurt horizontal plane, MSP-midsagittal plane, CP-coronal plane, Me- menton, Po-pogonion, B-Point B, Ma-Mandibular plane)

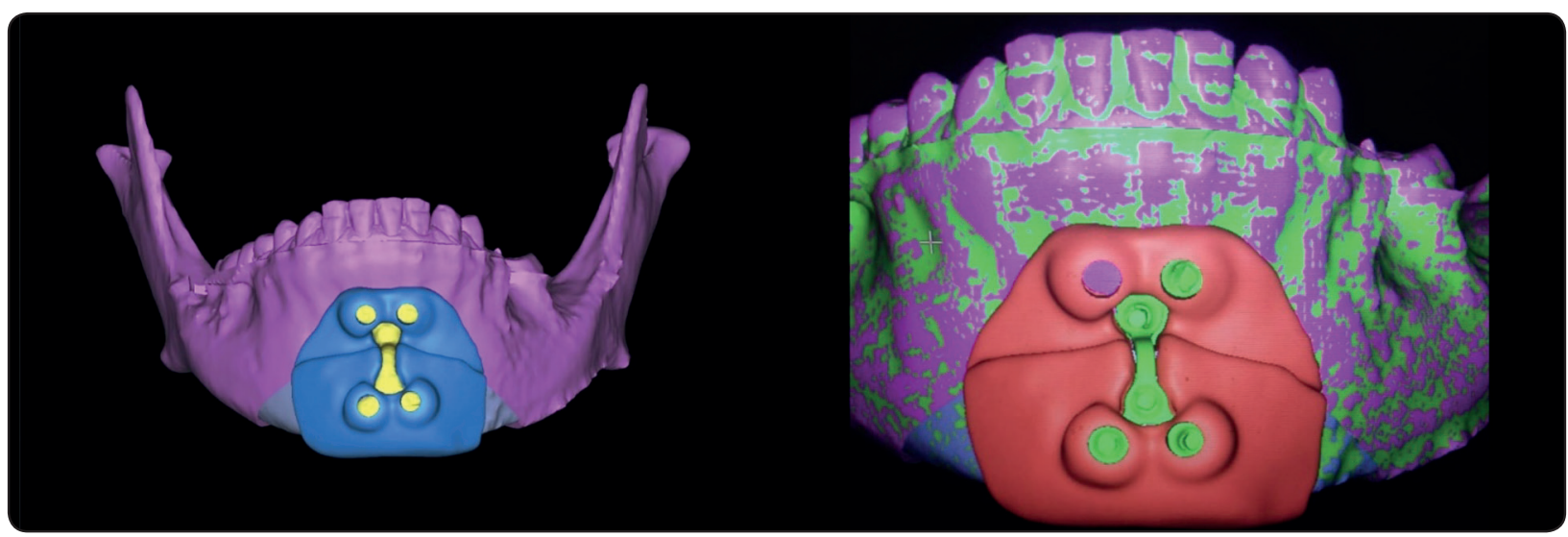

Fig. (6): Superimposition of the postoperative model onto the planning showed accurate positioning of the plate as seen on the right.

\section{DISCUSSION}

Orthognathic surgery and the improvement of facial esthetics has greatly evolved in the past decade. Chin surgeries (genioplasties) have benefited a lot from the improvement of Computer aided surgery and 3D printing technologies. As with most other orthognathic surgeries; genioplasties have a high risk of poor postoperative results due to innacuracies and improper chin positioning when compared to free hand surgery ${ }^{[9-12]}$. CAD CAM generated devices remain the accurate and more convenient solution for mandibular surgeries in general ${ }^{[13-15]}$. The specific use of surgical osteotomy guides in genioplasties has been reported with results supporting its use and advantages over conventional free-hand surgery ${ }^{[16-18]}$. The surgical guides reported in literature were used to ensure proper localization 
of the osteotomy cuts, be that using tooth \&/or bone supporting guides ${ }^{[7,19]}$.

The guides presented in our current study are bone-supported and together with the pre-bent plates guaranteed the ideal preplanned positioning of the chin segments and the location of the fixation plates. The Plate/chin segment-locating guide we assessed is quite a novel technique that allows the accurate placement of the prebent plate onto the improved chin position ${ }^{[3]}$.

Intraoperatively, although the guides used were properly utilized, double checking of location and the positioning of the final fixation plates was ensured. In none of our cases were there discrepancies between the planned positioning and the intraoperative location and all the guides and prebent plates were easily placed and fixed in position according to the preplanned screw hole locations. The guides fabricated in our study were designed with a wide bone-supported surface to enable better adaptation intraoperatively. Moreover, reference slots were designed to ensure accurate positioning of the chin osteotomy cuts. The protocol used in our study ensured triple checking of the plate fixation onto the relocated chin segment by the screw hole location, prebent design adaptation and plate/ chin segment guidance. A similar idea was reported in literature for mandibular orthognathic surgery (BSSO) and the results were promising $\left.{ }^{[14}\right]$. The third added plate/chin segment guide we introduce was used to ensure proper placing of the plate into its correct position overcoming the anatomic difficulties that may be faced to set the plate in place due to the chin segments. This guide prevented the sliding and rotation of the plate as it fixes the plate onto the target position which allowed for further accuracy of delivery of the virtual planning along with the osteotomy and screw-hole locating guides.

The location of the X-shaped plates was assessed by superimposing the postoperative $\mathrm{CT}$ images onto the virtual planning to identify the deviation. A mean deviation of 0.03 to $0.07 \mathrm{~mm}$ we noted in our study seems very acceptable clinically and proves that the surgical guides improvised in our study may be considered a method of improving clinical results of genioplasties. The postoperative assessment was based on surface-based registration of the pre- and post-operative CTs as reported earlier ${ }^{[20]}$. This technique was proven to be as accurate as voxelbased registration and surface-based registration methods.

\section{CONCLUSIONS}

The surgical osteotomy/screw-hole guide and plate/chin segment locating guide and pre-bent plates presented in this study allowed for accurate chin positioning surgeries and patient-satisfaction with the esthetic results as a result of that. These techniques proved especially helpful for less experienced surgeons.

\section{REFERENCES}

1. Ferretti C, Reyneke JP. Genioplasty. Atlas Oral Maxillofac Surg Clin North Am. 2016 Mar;24(1):79-85. doi: 10.1016/j.cxom.2015.10.008. PMID: 26847515.

2. Posnick JC, Choi E, Chang RP. Osseous genioplasty in conjunction with bimaxillary orthognathic surgery: a review of 262 consecutive cases. Int J Oral Maxillofac Surg. 2016 Jul;45(7):904-13. doi: 10.1016/j.ijom.2016.02.009. Epub 2016 Mar 10. PMID: 26972157.

3. Kraeima J, Glas HH, Witjes MJH, Schepman KP. Patient-specific pre-contouring of osteosynthesis plates for mandibular reconstruction: Using a three-dimensional key printed solution. J Craniomaxillofac Surg. 2018 Jun;46(6):1037-1040. doi: 10.1016/j.jcms.2018.03.022 . Epub 2018 Apr 6. PMID: 29716816.

4. PeacockZS, Magill JC, Tricomi BJ, Murphy BA,Nikonovskiy V, Hata N, Chauvin L, Troulis MJ. Assessment of the OsteoMark-Navigation System for Oral and Maxillofacial Surgery. J Oral Maxillofac Surg. 2015 Oct;73(10):200516. doi: 10.1016/j.joms.2015.03.017. Epub 2015 Mar 19. PMID: 25865717; PMCID: PMC4575615.

5. Qiao J, Fu X, Gui L, Girod S, Lee GK, Niu F, Liu J. Computer Image-Guided Template for Horizontal Advancement Genioplasty. J Craniofac Surg. 2016 Nov;27(8):2004-2008. doi: 10.1097/SCS.0000000000003093. PMID: 28005743. 
6. Assis A, Olate S, Asprino L, de Moraes M. Osteotomy and osteosynthesis in complex segmental genioplasty with double surgical guide. Int J Clin Exp Med. 2014 May 15;7(5):1197-203. PMID: 24995074; PMCID: PMC4073735.

7. Keyhan SO, Azari A, Yousefi P, Cheshmi B, Fallahi HR, Valipour MA. Computer-assisted horizontal translational osseous genioplasty: a simple method to correct chin deviation. Maxillofac Plast Reconstr Surg. 2020 Oct 20;42(1):36. doi: 10.1186/s40902-020-00278-z. PMID: 33102397 ; PMCID: PMC7575663.

8. Ghai S, Sharma Y, Jain N, Satpathy M, Pillai AK. Use of 3-D printing technologies in craniomaxillofacial surgery: a review. Oral Maxillofac Surg. 2018 Sep;22(3):249-259. doi: 10.1007/s10006-018-0704-z. Epub 2018 May 25. PMID: 29797107.

9. Bertossi D, Albanese M, Nocini R, Mortellaro C, Kumar N, Nocini PF. Osteotomy in Genioplasty by Piezosurgery. J Craniofac Surg. 2018 Jun 25. doi: 10.1097/ SCS.0000000000003150. Epub ahead of print. PMID: 29944550.

10. Richard O, Ferrara JJ, Cheynet F, Guyot L, Thiery G, Blanc JL. Complications des génioplasties [Complications of genioplasty]. Rev Stomatol Chir Maxillofac. 2001 Feb;102(1):34-9. French. PMID: 11345622.

11. Cheng A. Genioglossus and Genioplasty Advancement. Atlas Oral Maxillofac Surg Clin North Am. 2019 Mar;27(1):23-28. doi: 10.1016/j.cxom.2018.11.008. PMID: 30717920 .

12. Naran S, Steinbacher DM, Taylor JA. Current Concepts in Orthognathic Surgery.PlastReconstrSurg.2018Jun;141(6):925e936e. doi: 10.1097/PRS.0000000000004438. PMID: 29794714.

13. Brunso J, Franco M, Constantinescu T, Barbier L, Santamaría JA, Alvarez J. Custom-Machined Miniplates and Bone-Supported Guides for Orthognathic Surgery: A New Surgical Procedure. J Oral Maxillofac Surg.
2016 May;74(5):1061.e1-1061.e12. doi: 10.1016/j. joms.2016.01.016. Epub 2016 Jan 18. PMID: 26868183.

14. Abdel-Moniem Barakat A, Abou-ElFetouh A, Hakam MM, El-Hawary H, Abdel-Ghany KM. Clinical and radiographic evaluation of a computer-generated guiding device in bilateral sagittal split osteotomies. J Craniomaxillofac Surg. 2014 Jul;42(5):e195-203. doi: 10.1016/j. jcms.2013.08.007. Epub 2013 Sep 14. PMID: 24099655.

15. Polley JW, Figueroa AA. Orthognathic positioning system: intraoperative system to transfer virtual surgical plan to operating field during orthognathic surgery. J Oral Maxillofac Surg. 2013 May;71(5):911-20. doi: 10.1016/j. joms.2012.11.004. Epub 2013 Jan 10. PMID: 23312847.

16. Lim SH, Kim MK, Kang SH. Genioplasty using a simple CAD/CAM (computer-aided design and computer-aided manufacturing) surgical guide. Maxillofac Plast Reconstr Surg. 2015 Nov 24;37(1):44. doi: 10.1186/s40902-0150044-y. PMID: 26636050; PMCID: PMC4656692.

17. Yamauchi K, Yamaguchi Y, Katoh H, Takahashi T. Toothbone CAD/CAM surgical guide for genioplasty. Br J Oral Maxillofac Surg. 2016 Dec;54(10):1134-1135. doi: 10.1016/j. bjoms.2016.03.012. Epub 2016 Mar 26. PMID: 27025234.

18. Oth O, Durieux V, Orellana MF, Glineur R. Genioplasty with surgical guide using 3D-printing technology: A systematic review. J Clin Exp Dent. 2020 Jan 1;12(1):e85e92. doi: 10.4317/medoral.56145. PMID: 31976049; PMCID: PMC6969968.

19. Wang LD, Ma W, Fu S, Zhang CB, Cui QY, Peng CB, Li M. Design and manufacture of dental-supported surgical guide for genioplasty. J Dent Sci. 2021 Jan;16(1):417-423. doi: 10.1016/j.jds.2020.07.017. Epub 2020 Aug 22. PMID: 33384829; PMCID: PMC7770303.

20. Almukhtar A, Ju X, Khambay B, Mcdonald J, Ayoub A. Comparison of the Accuracy 298 of Voxel Based Registration and Surface Based Registration for 3D Assessment of 299 Surgical Change following Orthognathic Surgery. 2014;9(4):1-6. 300 doi:10.1371/journal.pone.0093402 